2012-08

\title{
Risk of fatal injury in older adult drivers, passengers, and pedestrians.
}

Rolison, JJ

http://hdl.handle.net/10026.1/1257

10.1111/j.1532-5415.2012.04059.x

J Am Geriatr Soc

All content in PEARL is protected by copyright law. Author manuscripts are made available in accordance with publisher policies. Please cite only the published version using the details provided on the item record or document. In the absence of an open licence (e.g. Creative Commons), permissions for further reuse of content should be sought from the publisher or author. 


\title{
Risk of Fatal Injury in Older Adult Drivers, Passengers, and Pedestrians
}

\author{
Jonathan J. Rolison, PhD, Paul J. Hewson, PhD, Elizabeth Hellier, PhD, ${ }^{\dagger}$ and \\ Poppy Husband, $M S c^{\mathcal{S}}$
}

OBJECTIVES: To compare risk of fatal injury in elderly road users (drivers, passengers, pedestrians) with that of younger age groups and to assess the contribution of elderly road users to the number of reported fatalities in the population.

DESIGN: Fatality age was categorized as 21 to 29,30 to 39,40 to 49,50 to 59,60 to 69 , or 70 and older, and road user was categorized as driver, passenger, or pedestrian. Estimated number of trips made by each age group was used to adjust for exposure and to measure individual risk.

SETTING: Fatalities recorded in Britain between 1989 and 2009.

PARTICIPANTS: Population-wide fatal injury counts in Britain.

MEASUREMENTS: Age of fatally injured drivers, passengers, and pedestrians. Estimated number of trips made per year by drivers, passengers, and pedestrians.

RESULTS: Risk of fatal injury, but not fatality numbers in the population, were higher for older adult $(\geq 70)$ drivers than for younger age groups. Risk of fatal injury was also high for older adult passengers and pedestrians, who represented the majority of older adult fatalities.

CONCLUSION: Previous emphasis on driver impairment in older age has unduly focussed attention on elderly drivers, who represent a minority of all driver fatalities. Older adults represent a much larger proportion of passenger and pedestrian fatalities. Additional policy schemes and initiatives should be targeted at safeguarding older adult passengers and making the road environment safer for elderly pedestrians. J Am Geriatr Soc 2012.

Key words: driver fatality rate; driving license; older drivers; road safety; road user fatalities

From the "School of Psychology, University IUAV of Venice, Venice, Italy; 'School of Computing and Mathematics, University of Plymouth, Plymouth, UK; ${ }^{\text {*S }}$ chool of Psychology, University of Plymouth, Plymouth, UK; and ${ }^{\S}$ Devon Drivers Centre, Devon County Council, Devon, UK.

Address correspondence to Jonathan J. Rolison, University IUAV of Venice, convento delle Terese, 30123 Venice, Italy.

E-mail: jonathan.rolison@plymouth.ac.uk

DOI: $10.1111 / \mathrm{j} .1532-5415.2012 .04059 . \mathrm{x}$
$M$ ore than 1,800 road accident fatalities were reported in Britain in 2010. ${ }^{1}$ Older adults are at greater risk than younger adults as drivers. Population data show that, for each trip taken, older adults $(\sim \geq 70)$ are at greater risk of fatal injury than younger individuals. ${ }^{2-4}$ Cognitive impairment (e.g., dementia) is more prevalent in older adults, and visual acuity is compromised..$^{5}$ Both are risk factors that could, in principle, lead to impaired driving and fatal injury. The response by policy-makers to this evidence has been to regulate license renewal for older adults. ${ }^{6,7}$ There is also a shift toward routine screening for cognitive and visual impairment in older age, ${ }^{8}$ and medical practitioners are increasingly called to make important decisions about the driving privileges of elderly persons. ${ }^{8}$

An unintended outcome of license renewal legislations has been to discourage unimpaired older adults from renewing their vehicle licenses. ${ }^{9}$ Mobility, which loss of driving privileges compromises, is strongly linked to well-being ${ }^{10}$ and multiple health outcomes. ${ }^{11,12}$ License renewal legislation is effective for older adults who are impaired and may safeguard them from potential injury, but license renewal legislation comprises the mobility of all older adults, many of whom may be unimpaired, directly affecting their physical health and quality of life.

Although for each trip taken, elderly drivers are at greater risk of fatal injury, they represent a small proportion of all drivers. As well as driving less frequently than younger adults, ${ }^{13}$ elderly drivers regulate their exposure to risk by avoiding challenging driving conditions such as poor weather. ${ }^{14,15}$ With fewer elderly drivers and with their reduced exposure to risk by self-regulation, the number of elderly driver fatalities in the population-where public health legislation will be effective-may not reflect the higher fatality rates of elderly drivers. As a result, policy initiatives, such as license renewal legislation and screening for cognitive and visual impairment, which are targeted at elderly drivers, may have little effect on overall fatality numbers. With older adults making fewer trips as drivers, fatality numbers may be higher for elderly 
passengers and pedestrians than for drivers, despite the emphasis on elderly drivers. If this is correct, then policy regulations would be more effective if targeted at protecting older adult passengers and pedestrians (as well as drivers), who may represent a much larger proportion of all elderly fatalities.

The current study compared risk of fatal injury of elderly road users (drivers, passengers, pedestrians) with those of younger individuals and investigated their contribution to overall fatality numbers in the population. It was hypothesized that, for drivers, risk of fatal injury but not fatality numbers in the population would be high for older adults and that elderly passengers and pedestrians would represent a larger proportion of fatalities in the population than elderly drivers.

\section{METHODS}

\section{Data Source}

The University of Essex Data Archive provided the raw fatality data for road traffic crashes in Britain (England, Scotland, and Wales) between 1989 and 2009. Police officers collected the data on location. Data collection guidelines specify that deaths that occur within 30 days of an incident are classified as road traffic fatalities. ${ }^{16}$ Deaths that result from natural causes are not counted as road traffic fatalities. The local processing authority (police, local authority, contractor) makes arrangements to provide the casualty data to the UK Department for Transport (DfT). ${ }^{17}$ The resulting raw data are referred to as STATs 19 data and are summarized for public consumption. The UK DfT provided the measures of exposure, which included the estimated number of trips made per year by drivers, passengers (of cars only), and pedestrians between 1989 and 2009 for each age band (21-29, $30-39,40-49,50-59,60-69, \geq 70)$. These data were collected as part of the UK National Travel Survey, ${ }^{17}$ in which respondents recorded trips made using a travel diary. Trips that were less than $1 \mathrm{~km}$ long were excluded.

\section{Statistical Analysis}

For the statistical analysis, generalized linear Poisson regression was conducted with log-link modelling on fatalities, as advised previously ${ }^{18}$ for count data. In all of the regression analyses, age group was introduced as a factor. Following the UK DfT, fatality age was categorized as 21 to 29,30 to 39,40 to 49,50 to 59,60 to 69 , or 70 and older, omitting the youngest drivers (17-20). Fatality rates for these individuals are known to be high, and the focus here is on the older age groups. The analysis of overall fatality numbers in the population included road user (driver, passenger, pedestrian) as a factor and year (19892009) as a covariate. The analysis of fatality rates per trip also included the estimated number of trips that drivers, passengers, and pedestrians made as an offset term. For all of the analyses, the factors and the covariate were introduced in a first block to test for their main effects. All possible interaction terms were then introduced in a second block.

\section{RESULTS}

\section{Driver, Passenger, and Pedestrian Fatality Rates per Trip}

The Poisson regression analysis revealed that risk of fatal injury per trip was 1.27 times as great for drivers as for passengers $(95 \%$ confidence interval $(\mathrm{CI})=1.16-1.40)$ and 1.15 times as great for pedestrians as for drivers $(95 \%$ $\mathrm{CI}=1.07-1.24)$ but fell from 1989 to $2009(\mathrm{OR}=0.76$, $95 \% \mathrm{CI}=0.75-0.77$ ). Risk of fatal injury (including drivers, passengers, and pedestrians) was lower for individuals aged 21 to $29(\mathrm{OR}=0.58,95 \% \mathrm{CI}=0.52-0.64), 30$ to $39(\mathrm{OR}=0.32, \quad 95 \% \quad \mathrm{CI}=0.29-0.35), \quad 40 \quad$ to 49 $(\mathrm{OR}=0.24,95 \% \mathrm{CI}=0.22-0.27), 50$ to $59(\mathrm{OR}=0.25$, $95 \% \mathrm{CI}=0.23-0.29)$, and 60 to $69(\mathrm{OR}=0.32,95 \%$ $\mathrm{CI}=0.28-0.36)$ than for those aged 70 and older. Risk of fatal injury was greater for elderly drivers, passengers, and pedestrians than for younger individuals (Figure 1A).

Road user (driver, passenger, pedestrian) as a factor interacted with age. Comparisons between adults aged 70 and older and those aged 21 to 29 interacted with comparisons between drivers and pedestrians $(\mathrm{OR}=4.35,95 \%$ $\mathrm{CI}=3.62-5.23)$ and between passengers and pedestrians $(\mathrm{OR}=4.66,95 \% \mathrm{CI}=3.76-5.79)$ but not between drivers and passengers $(\mathrm{OR}=0.93,95 \% \mathrm{CI}=0.76-1.14)$. The interaction effects are apparent in Figure 2, which shows fatality rates for 1989 to 2009. Follow-up analysis conducted separately on each road-user type revealed that individuals aged 70 and older were 5.19 times as likely to be fatally injured per trip made as a pedestrian as those aged 21 to $29(95 \% \mathrm{CI}=5.16-5.22)$, but for drivers $(\mathrm{OR}=1.01, \quad 95 \% \quad \mathrm{CI}=0.91-1.13) \quad$ and passengers $(\mathrm{OR}=0.93,95 \% \mathrm{CI}=0.85-1.02)$, risk of fatal injury was not significantly different for individuals aged 70 and older and those aged 21 to 29. Fatality rates for drivers and passengers were highest for the youngest (21-29) and oldest $(\geq 70)$ age groups, but as the analysis indicates, this trend is not apparent for pedestrians (Figure 2). The fatality rates of pedestrians are higher only for the oldest age group ( $\geq 70$; Figure 2 ), indicating that elderly individuals are at greater risk of fatal injury as pedestrians than younger age groups.

\section{Driver, Passenger, and Pedestrian Fatality Numbers in the Population}

The Poisson regression analysis on fatality numbers in the population revealed that driver fatalities were significantly more frequent (overall average of 1,603.6 fatalities per year) than passenger (443.2 fatalities per year; $\mathrm{OR}=3.57$, $95 \% \mathrm{CI}=3.23-4.17)$ and pedestrian (780.0 fatalities per year; $\mathrm{OR}=2.04,95 \% \mathrm{CI}=1.85-2.27)$ fatalities and that overall fatality numbers fell from 1989 (4,046 fatalities overall) to 2009 (1,815 fatalities overall; OR $=0.97,95 \%$ $\mathrm{CI}=0.96-0.98)$. Fatality numbers were lower for the groups aged 30 to $39(\mathrm{OR}=0.84,95 \% \mathrm{CI}=0.73-0.97)$, 40 to $49(\mathrm{OR}=0.61,95 \% \mathrm{CI}=0.52-0.71), 50$ to 59 $(\mathrm{OR}=0.49, \quad 95 \% \quad \mathrm{CI}=0.04-0.06), \quad$ and 60 to 69 $(\mathrm{OR}=0.43,95 \% \mathrm{CI}=0.36-0.51)$ than for the group aged 70 and older and were higher only for the group ages 21 to $29(\mathrm{OR}=1.14,95 \% \mathrm{CI}=1.00-1.30)$. 
Panel A: Driver, Passenger, and Pedestrian Fatality Rates per 100 Million Trips
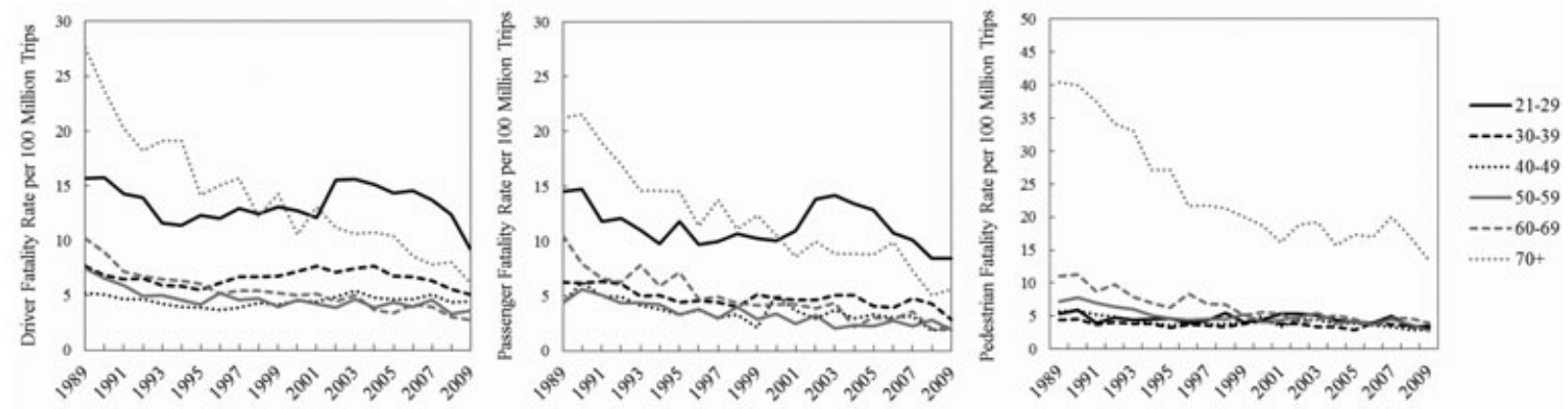

Panel B: Driver, Passenger, and Pedestrian Fatality Counts in the Population
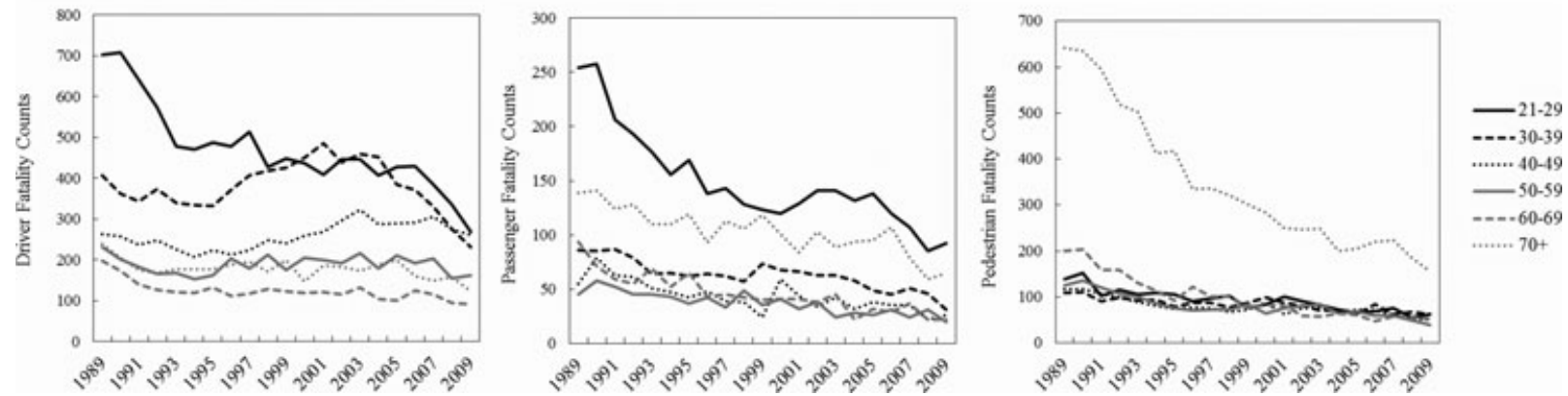

Figure 1. Driver, passenger, and pedestrian fatalities (A) per trip and (B) in the population according to age group.
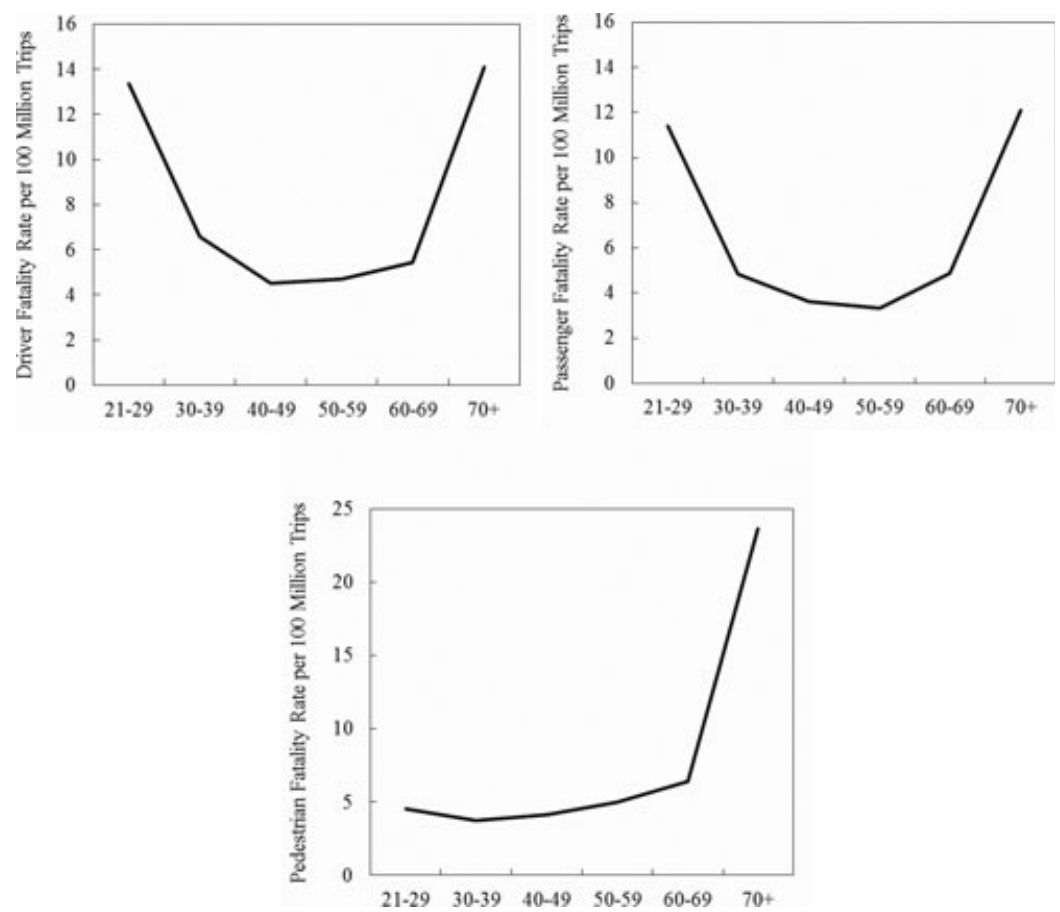

Figure 2. Driver, passenger, and pedestrian fatality rates according to age group per 100 million trips: 1989 to 2009.

Road user as a factor interacted with each of the age groups. Older adults $(\geq 70)$ represented the highest proportion of pedestrian fatalities, with more fatalities than in the groups aged 21 to $29(\mathrm{OR}=3.70,95 \%$ $\mathrm{CI}=3.45-4.00), 30$ to $39(\mathrm{OR}=4.17,95 \% \mathrm{CI}=3.70$ $4.55), 40$ to $49(\mathrm{OR}=4.35,95 \% \mathrm{CI}=4.00-4.76), 50$ to $59(\mathrm{OR}=4.35,95 \% \mathrm{CI}=3.85-4.76)$, and 60 to 69
$(\mathrm{OR}=3.45,95 \% \mathrm{CI}=3.23-3.85)$. There were four times as many older adult $(\geq 70)$ pedestrian fatalities than for all younger age groups combined (21-69; Figure 1B).

The older adults $(\geq 70)$ also represented the second largest proportion of passenger fatalities, with more fatalities than the groups aged 30 to 39 (OR $=1.64,95 \%$ $\mathrm{CI}=1.52-1.79), 40$ to $49(\mathrm{OR}=2.38,95 \% \mathrm{CI}=2.17-$ 
2.63), 50 to $59(\mathrm{OR}=2.78,95 \% \mathrm{CI}=2.50-3.13)$, and 60 to $69(\mathrm{OR}=2.27,95 \% \mathrm{CI}=2.08-2.50)$, except for the group aged 21 to $29(\mathrm{OR}=0.69,95 \% \mathrm{CI}=0.65-0.74)$. There were 1.4 times as many passenger fatalities for the youngest age group (21-29) as for the oldest age group $(\geq 70)$ but 2.2 times as many passenger fatalities for the oldest age group as for those aged 30 to 69 (age categories combined). Thus, in addition to representing the largest proportion of all pedestrian fatalities, older adults also represented a large proportion of all passenger fatalities.

Driver fatality numbers, in contrast, reduced with age, such that fatality numbers were higher for the groups aged 21 to $29(\mathrm{OR}=2.66,95 \% \mathrm{CI}=2.41-2.94), 30$ to 39 $(\mathrm{OR}=2.14, \quad 95 \% \quad \mathrm{CI}=1.93-2.37), \quad$ and 40 to 49 $(\mathrm{OR}=1.46,95 \% \mathrm{CI}=1.31-1.63)$ but not those aged 50 to $59(\mathrm{OR}=1.05,95 \% \mathrm{CI}=0.93-1.18)$ and were lower only for the group aged 60 to 69 (OR $=0.70,95 \%$ $\mathrm{CI}=0.61-0.80)$. There were 2.1 times as many driver fatalities for those aged 21 to 49 as for those aged 70 and older. This is further shown in Figure $1 \mathrm{~B}$, where fatality numbers in the population can be seen to be proportionally higher for older adults than for the younger age groups, but only for passengers and pedestrians, not for drivers.

\section{DISCUSSION}

Fatalities in the population are fewer for older adult drivers $(\geq 70)$ than younger age groups, and driver fatality numbers reduced steadily with age (left side Figure 1B). Older adults instead represented the second largest proportion of all passenger fatalities in the population (middle Figure 1B) and a much larger proportion of all pedestrian fatalities than any other age group (right side Figure 1B). When adjusting for number of trips made by drivers, the analyses indicate that elderly driver fatalities in the population are fewer in part because older adults regulate their exposure to risk by driving less frequently. Nonetheless, risk of fatal injury per trip made as a driver was higher for older adults than for younger age groups. The current findings emphasize the importance of public health initiatives targeted at safeguarding elderly drivers and indicate that additional policies and initiatives are needed to safeguard older adult passengers and pedestrians, shown presently to represent a much larger proportion of elderly fatalities.

Tighter regulations on license renewals imposed by policy-makers and screening for cognitive and visual impairment are targeted specifically at elderly drivers, ${ }^{6-8}$ but the current findings revealed that driver fatality numbers in the population fell with age. Older adults represent a minority of all driver fatalities. The greater risk of fatal injury in older adult drivers is an important health concern, but previous emphasis on driver fatality rates, ${ }^{2-4}$ which guides policy decisions, ignores risks that elderly passengers and pedestrians, who represent the majority of elderly fatalities, face.

Risk of fatal injury per trip made was highest for the youngest (21-29) and oldest $(\geq 70)$ age groups for drivers and passengers but was high only for elderly pedestrians (Figure 2). Older adults who die may be the passengers of impaired elderly drivers. Whether the causes of high fatality rates of elderly drivers and passengers also explain those of elderly pedestrians is complex. Older adult pedestrians are found to make poorer decisions at road crossings than younger adults by attending more to the distance of an approaching vehicle than to its approaching speed. ${ }^{19,20}$ Older adults also have a slower walking pace than younger individuals. ${ }^{21}$ It is likely that both factors combined are causes of the higher fatality rates of elderly pedestrians reported presently. The above findings also point to practical solutions for reducing the risks that elderly pedestrians face, such as increasing the crossing time at signalled crossings and introducing traffic islands on busy roads in inner-city areas. ${ }^{21}$

An interesting twist to the findings is that fatality rates (per trip) for elderly drivers reduced sharply in the British population between 1989 and 2009 (left side Figure 1A). This trend does not coincide with the introduction of license renewal policy for drivers aged 70 , which was introduced in January $1976 .{ }^{22}$ Why this trend in fatality rates occurred and whether it applies also for other populations can only be speculated, but if the same analysis had been conducted in the 1990s, a much stronger claim for higher driver fatality rates in older age would have been made. (Observe the trend line for drivers aged $\geq 70$.) A number of published articles make strong claims for higher older adult fatality rates during this period. $^{3,4}$ In contrast, the results of the current study also reveal that fatality numbers in the population for drivers aged 70 and older (left side Figure 1B) were relatively flat between 1989 and 2009. Although risk of fatal injury in elderly drivers has reduced sharply over the past 20 years, overall fatality numbers for older adults in the population have not changed, indicating that fatality rates do not necessarily correspond to overall fatality numbers in the population.

The current study is ecological and has a number of limitations. Although the data suggest that older adults regulate their exposure to risk by driving less frequently, it is possible that impaired older adults drive less frequently than those who are unimpaired, leading to underestimation of their fatality rates. The casualty data also rely on casualties being reported accurately to the police, and the reliability of the exposure data depends on whether journeys are accurately recorded. Nevertheless, any inaccuracies in reporting should apply equally to drivers, passengers, and pedestrians and should not have affected comparisons between age groups and road users. Moreover, the data analyzed presently provide the most reliable statistics available in Britain.

Driver fatality rates were highest for the youngest and oldest age groups. It is likely that inexperience, and perhaps risky driving behavior, explains these rates for young drivers, whereas driver impairment and other factors may explain the greater risk of fatal injury in elderly drivers, although it is also possible that age groups differ in the injury prevention features that their vehicles provide. Safety features such as front air bags ${ }^{23}$ (and air bag generation $\left.{ }^{24}\right)$, seat belt status, and vehicle age and design $^{25}$ may have confounded the comparisons between age groups. Further research would benefit from investigating these variables as moderating factors on fatal injury.

A major strength of the present study is that number of trips made by road users (drivers, passengers, pedestrians) 
was used to calculate risk of fatal injury. Estimates that are based on number of registered license holders assume that vehicle usage is similar for all age groups. Nevertheless, despite the benefits of the use of exposure measures, it is possible that there are systematic differences between age groups in their distance traveled, in which older age groups would be expected to take shorter journeys. Further research may benefit from combining estimates of the number trips made with distance travelled.

In conclusion, despite higher fatality rates for elderly drivers, older adult drivers represent a minority of driver fatalities in the population. Previous emphasis placed on driver fatality rates has unduly focused attention on identifying and controlling driver impairment in older age. The findings of the current study reveal that passenger and pedestrian fatality numbers are higher in older adults than in younger age groups and account for the majority of elderly fatalities. In addition to continued policies and initiatives targeted at safeguarding elderly drivers, steps are needed to safeguard elderly passengers and make the road environment safer for elderly pedestrians. New schemes and initiatives should be targeted at safeguarding all elderly road users.

\section{ACKNOWLEDGMENTS}

We thank Michael Hyland for helpful comments on earlier drafts of the article.

Conflict of Interest: The authors do not perceive any actual or potential conflicts of interest.

Author Contributions: Jonathan J. Rolison drafted the manuscript, contributed to conception and design of the study, and conducted the data analysis. Paul J. Hewson contributed to data analysis, conception and design of the study, and editing of the manuscript. Elizabeth Hellier edited the manuscript and contributed to the conception and design of the study. Poppy Husband conducted literature searches.

Sponsor's Role: None.

\section{REFERENCES}

1. Department for Transport. Reported Road Casualties in Great Britain: the Main Results 2010 [on-line]. Available at http://www.dft.gov.uk/statistics/ releases/road-accidents-and-safety-annual-report-2010 Accessed September 27, 2011.

2. Lyman S, Ferguson SA, Braver ER, Williams A. Older driver involvement in police reported crashes and fatal crashes: Trends and projections. Inj Prev 2002;8:116-120.
3. Evans L. Risks older drivers face themselves and threats they pose to other road users. Int J Epidemiol 2000;29:315-322.

4. Massie DL, Campbell KL, Williams AF. Traffic accident involvement rates by driver age and gender. Accid Anal Prev 1995;27:73-87.

5. Anstey KJ, Wood J, Lord S et al. Cognitive, sensory, and physical factors enabling driving safety in older adults. Clin Psychol Rev 2005;25:45-65.

6. DVLA. Driving and Vehicle Licensing Authority [on-line]. Available at http://www.direct.gov.uk/en/Motoring/DriverLicensing/NeedANewOrUpdatedLicence/DG_4022086 Accessed September 27, 2011.

7. Highway Safety Research and Communications. Older Drivers: License Renewal Provisions[on-line]. Available at http://www.iihs.org/laws/olderdrivers.aspx Accessed September, 27, 2011.

8. Carr DB, Ott BR. The older adult driver with cognitive impairment: It's a very frustrating life. JAMA 2010;303:1632-1641.

9. Ross LA, Browning C, Luszcz MA et al. Age-based testing for driver's license renewal: Potential implications for older Australians. J Am Geriatr Soc 2011;59:281-285.

10. Oxley J, Whelan M. It cannot be all about safety: The benefits of prolonged mobility. Traffic Inj Prev 2008;9:367-378.

11. Berkman LF. Assessing the physical health effects of social networks and social support. Annu Rev Public Health 1984;5:413-432.

12. Kaplan GA. Where do shared pathways lead? Some reflections on a research agenda. Psychosom Med 1995;57:208-212.

13. Rimmö PA, Hakamies-Blomqvist L. Older drivers' aberrant driving behaviour, impaired activity, and health as reasons for self-imposed driving limitations. Transp Res Part F Traffic Psychol Behav 2002;5:345-360.

14. Baldock MRJ, Mathias JL, McLean AJ et al. Self-regulation of driving and its relationship to driving ability among older drivers. Accid Anal Prev 2006;38:1038-1045.

15. Raitanen T, Tormakangas T, Mollenkopf $\mathrm{H}$ et al. Why do older adult drivers reduce driving? Findings from three European countries. Transp Res Part F Traffic Psychol Behav 2003;6:81-95.

16. UK Department for Transport. Instructions for the completion of road accident reports[on-line]. Available at http://www2.dft.gov.uk/pgr/statistics/ datatablespublications/accidents/casualtiesgbar/s20instructionsforthecom5094.pdf Accessed September 27, 2011.

17. UK Department for Transport. National Travel Survey[on-line]. Available at http://www.dft.gov.uk/statistics/releases/national-travel-survey-2010 Accessed September 27, 2011.

18. McCullagh P, Nelder JA. Generalized Linear Models, 2nd Ed. London: Chapman \& Hall, 1989.

19. Dommes A, Cavallo V. The role of perceptual, cognitive, and motor abilities in street-crossing decisions of young and older pedestrians. Ophthalmic Physiol Opt 2011;31:292-301.

20. Oxley J, Fildes B, Ihsen E et al. Differences in traffic judgments between young and old adult pedestrians. Accid Anal Prev 1997;29:839-847.

21. Langlois JA, Keyl PM, Guralnik JM et al. Characteristics of older pedestrians who have difficulty crossing the street. Am J Public Health 1997;87:393-397.

22. UK Department of Transport. Development of British Driving and Road Safety [on-line]. Available at http://www.dft.gov.uk/publications/dsadevelopment-british-driving-road-safety Accessed September 27, 2011.

23. Cummings P, McKnight B, Rivara FP et al. Association of driver air bags with driver fatality: A matched cohort study. BMJ 2002;324:1119-1122.

24. Braver EA, Kufera JA, Alexander MT et al. Using head-on collisions to compare risk of driver death by frontal air bag generation: A matched-pair cohort study. Am J Epidemiol 2008;167:546-552.

25. Famer CM, Lund AK. Trends over time in the risk of driver death: What if vehicle designs had not improved? Traffic Inj Prev 2006;7:335-342. 